\title{
Design of vehicle using Ackermann steering with IoT concept
}

\author{
Albert Paul Arunkumar, Palanisamy R., Selvakumar K., Usha S., Thamizh Thentral T. M., \\ Karthikeyan D. \\ Department of EEE, SRM Institute of Science and Technology, Kattankulathur, India
}

\begin{tabular}{l} 
Article Info \\
\hline Article history: \\
Received May 19, 2021 \\
Revised Oct 29, 2021 \\
Accepted Nov 1, 2021
\end{tabular}

\section{Keywords:}

Ackermann steering

Arduino Uno

IoT

Sensors

Vehicle

\begin{abstract}
Electric vehicles are becoming more demanding these days. In this project the possibility of using Ackerman steering with electric drive servomotor is explained. Scalability is the advantage of using this mechanism which can be adopted for four-wheel vehicle system as well. The objective of this project is to do design a system using Ackerman steering which determines the maximum and minimum angle of the turning of the wheels. It also avoids the front tire slippage and activates pure rolling. Ackermann steering geometry is a geometric arrangement of linkages in the steering of a car or other vehicle designed to solve the problem of wheels on the inside and outside of a turn needing to trace out circles of different radii. The geometrical solution to this is for all wheels to have their axles arranged as radii of circles with a common centre point. As the rear wheels are fixed, this centre point must be on a line extended from the rear axle. Intersecting the axes of the front wheels on this line as well requires that the inside front wheel be turned, when steering, through a greater angle than the outside wheel. The microcontroller used in this project is ATMega16 and max232 is used for the serial data transmission.
\end{abstract}

This is an open access article under the CC BY-SA license.

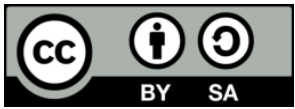

\section{Corresponding Author:}

Palanisamy R.

Department of EEE

SRM Institute of Science and Technology

Kattankulathur, India

Email:krspalani@gmail.com

\section{INTRODUCTION}

Due to increased uses of vehicles and transportation the research of vehicle's stability and controllability are demanded [1]. The past researches were based on proper mechanical systems only. The conventional accessories of mechanical link are now being replaced by the electronic link by signal modules [2]-[5]. The heavy equipments present in the vehicle are now being replaced by the microcontroller signals, and servo motors to obtain characteristic data and to advance the performance of electric vehicle system, the research of modelling which replace mechanic linkage system by electronic signal system is active recently [6]-[9].

The mechanical steering is a combination on worm gear and nut [10]. The turning angle is determined by the pitch movement and pitch length and the rotation of the steering and with the gear ratio the wheel rotate about its vertical axis [11]-[14]. This system contains frictional losses and also an offset can be seen but if replaced with electronic system it will get a feedback system and the least count (L.C) of 1/10th of a micron which is very small as an offset [15]. The mechanical gears and nuts can be replaced by industrial grade servo's and an electronic feedback system which takes an Analog input from the steering wheel find the angle of the steering wheel and using the Ackermann's geometry we can find out the angle of rotation of 
the wheel and also the radius or curvature of turning for the car and the individual wheels [16]-[18]. The Figure 1 shows the Ackerman steering positioning.

To achieve true rolling for a four wheeled vehicle moving on a curved track, the lines drawn through each of the four wheel axes must intersect at the instantaneous centre [19]. The actual position the instantaneous centre constantly changes due to the alternation of the front wheel angular positions to correct the steered vehicle's path. Since both rear wheels are fixed on the same axis but the front wheel axles are independent of each other, the instantaneous centres lies somewhere along an imaginary extended line drawn through the axis of the rear axle [20]-[22].

The Ackermann principle is based on the two front steered wheels being pivoted at the ends of an axle-beam. The original Ackermann linkage has parallel set track-rod-arms, so that both steered wheels swivel at equal angles [23]-[26]. Consequently, the intersecting projection lines do not meet at one point. If both front wheels are free to follow their own natural paths, they would converge and eventually cross each other. Since the vehicle moves along a single mean path, both wheel tracks conflict continuously with each other causing tyre slip and tread scrub. Subsequent modified linkage uses inclined track-rod arms so that the inner wheel swivels about its king-pin slightly more than the outer wheel. Hence the lines drawn through the stub-axles converge at a single point somewhere along the rear-axle projection.

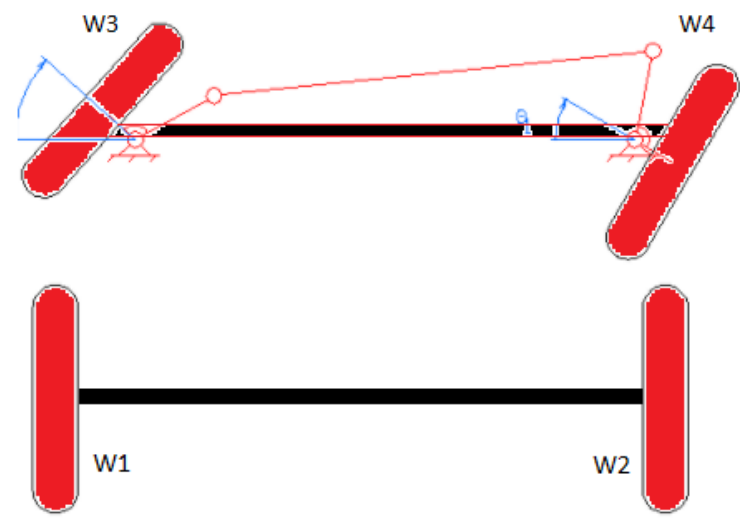

Figure 1. Ackerman steering positioning

\section{PROPOSED SYSTEM}

The basic working of the Ackermann electronic steering is done using two servo motors and an absolute encoder, which in this case is a potentiometer and a $1.2 \mathrm{~kg} / \mathrm{cm}$ torque servo motor, one servo motor for each wheel. The mathematical model of this steering includes the angle of rotation of the steering wheel thus getting angle of rotation of each wheel. The angle of rotation of each wheel is different as each wheel points towards the same center of radius of curvature thus making individual hypotenuse different in length. The angle of each wheel depends on the length and the width of the car and the radius of curvature of individual wheel. These equations can further be used to model electronic differential. The variable voltage input from the potentiometer gives the angle of rotation of the wheel, this angle then is used to find the angle of rotation of left wheel and right wheel and also the radius of curvature.

The simplest connection between a PC and microcontroller requires a minimum of three pins, RxD (receiver, pin2), TxD (transmitter, pin3) and ground (pin5) of the serial port of computer. TxD pin of serial port connects to RxD pin of controller via MAX232. And similarly, RxD pin of serial port connects to the TxD pin of controller through MAX232. Block diagram of Ackerman steering is shown in Figure 2.

MAX232 has two sets of line drivers for transferring and receiving data. The line drivers used for transmission are called $\mathrm{T} 1$ and $\mathrm{T} 2$, where as the line drivers for receiver are designated as R1 and R2. The rate at which the serial data is being transferred is called the baud rate. The interfacing is done as first the baud rate is selected and the corresponding urban disaster risk reduction (UDRR) value is written to set up a baud rate at ATMega16 microcontroller. Pin diagram of ATMega16 is shown in Figure 3. Universal synchronous asynchronous receiver transmitter (USART) is initialized by turning on transmission circuitry and selecting the no of stop bits. The size of the data is selected and value of UDDR is set as baud rate. The data is received from the USART flag is monitored. RXC (type of receiver) flag is high when there is a stop bit signal therefore the data is loaded. 


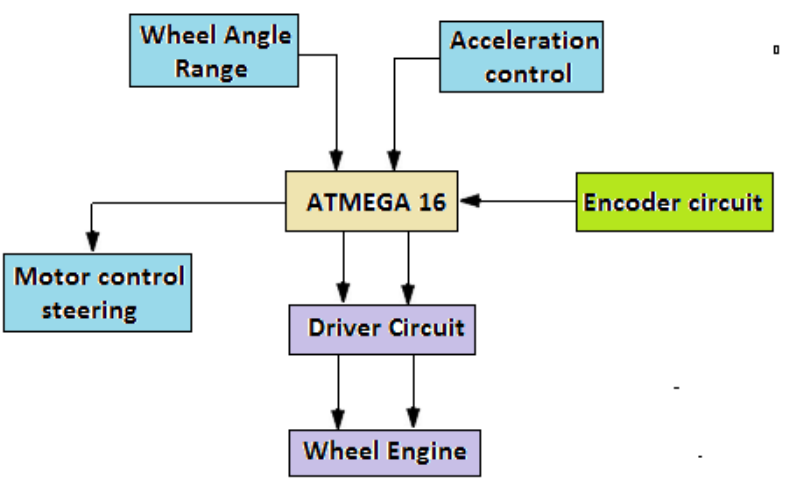

Figure 2. Block diagram of Ackerman steering

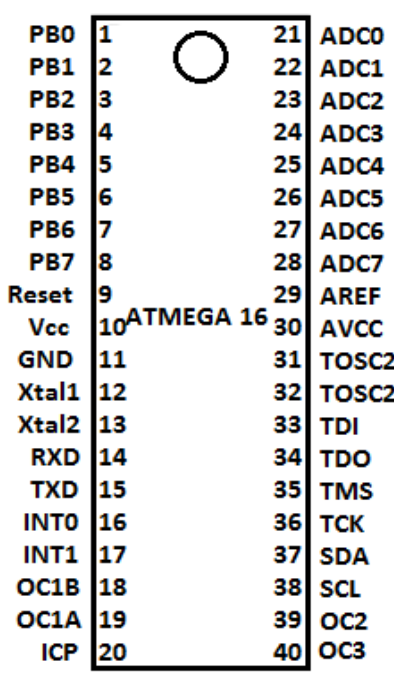

Figure 3. Pin diagram of ATMega 16

\section{CONTROL TECHNIQUE}

ATMegal6 is an 8-bit high performance microcontroller of Atmel's Mega AVR family with low power consumption. ATMegal6 is based on enhanced reduced instruction set computing (RISC) architecture with 131 powerful instructions. Most of the instructions execute in one machine cycle [24]-[26]. ATMega16 can work on a maximum frequency of $16 \mathrm{vMHz}$. ATMega16 has $16 \mathrm{~kb}$ programmable flash memory, static RAM of $1 \mathrm{~KB}$ and electrically erasable programmable read-only memory (EEPROM) of 512 Bytes. The endurance cycle of flash memory and EEPROM is 10,000 and 100,000, respectively. Interfacing of ATmegal6 with Ackerman steering is shown in Figure 4. ATMega16 is a 40 pin microcontroller. There are 32 input/output (I/O) lines which are divided into four 8-bit ports designated as PORTA, PORTC and PORTD (pin numbers). ATMega16 haslvarious in-built peripherals like USART and analog to digital converter (ADC). Each I/O pin has an alternative task related to in-built peripherals. The following Table 1 shows various angles are obtained from Ackerman steering.

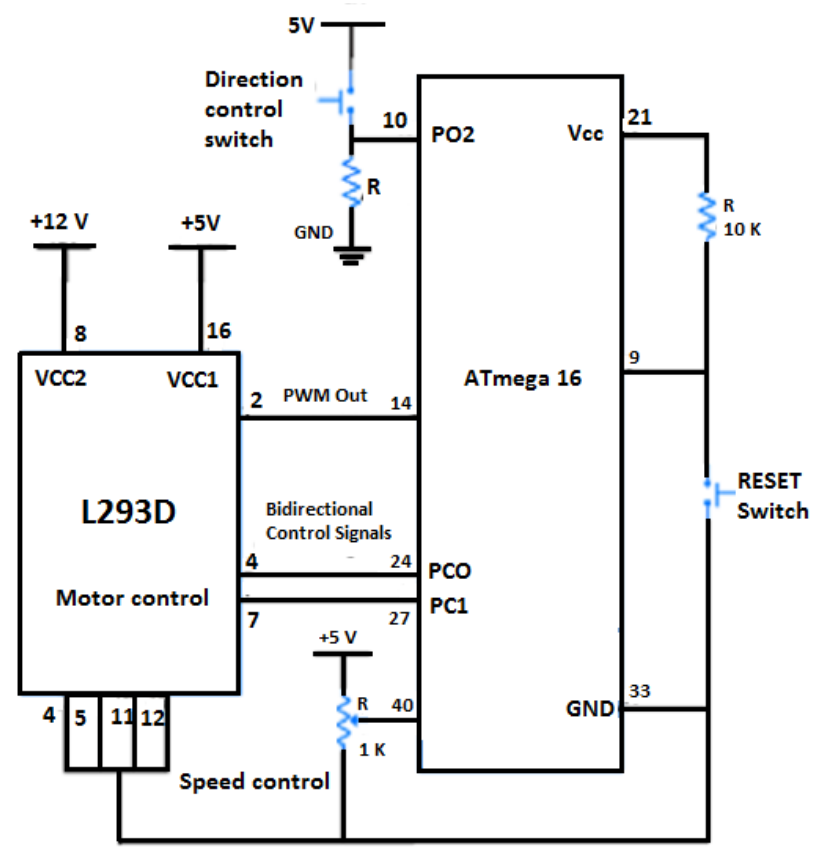

Figure 4. Interfacing of ATMega16 with Ackerman steering 
Table 1. Various angles are obtained from Ackerman steering

\begin{tabular}{cccccc}
\hline delta & Ro & $\mathrm{d} 1$ & $\mathrm{~d} 2$ & Rleft & Rright \\
\hline 80 & 0.277665 & 1.02228 & -1.19987 & 1.527665 & -0.97233 \\
75 & -5.94246 & -0.48952 & -0.33452 & -4.69246 & -7.19246 \\
70 & 2.045894 & 0.648931 & 1.262584 & 3.295894 & 0.795894 \\
65 & -1.70064 & -1.39246 & -0.70291 & -0.45064 & -2.95064 \\
60 & 7.811514 & 0.269195 & 0.364029 & 9.061514 & 6.561514 \\
55 & -0.05533 & 1.125011 & -1.0896 & 1.19467 & -1.30533 \\
50 & -9.19454 & -0.30487 & -0.23494 & -7.94454 & -10.4445 \\
45 & 1.543424 & 0.730023 & 1.453961 & 2.793424 & 0.293424 \\
40 & -2.23771 & -1.19454 & -0.62191 & -0.98771 & -3.48771 \\
35 & 5.276324 & 0.365822 & 0.555655 & 6.526324 & 4.026324 \\
30 & -0.3903 & 1.239584 & -0.99013 & 0.8597 & -1.6403 \\
25 & -18.7229 & -0.14211 & -0.12452 & -17.4729 & -19.9729 \\
20 & 1.117488 & 0.812615 & -1.51784 & 2.367488 & -0.13251 \\
15 & -2.92058 & -0.98171 & -0.54001 & -1.67058 & -4.17058 \\
10 & 3.855878 & 0.455319 & 0.764665 & 5.105878 & 2.605878 \\
5 & -0.73953 & 1.369378 & -0.89861 & 0.510468 & -1.98953 \\
\hline
\end{tabular}

In this project the two servomotors are connected to two wheels which determine the angle of rotation by the variation of voltage through the potentiometer. On turning the speed, the inner wheel slows down and speed of the outer wheel rises up in proportional to the actual angular velocity. A positional encoder is used for the steering, which gives us the angle of turning of the car. As it takes turn both the front wheels point out to same center $\mathrm{C}$ of turning making their radius from $\mathrm{C}$. thus forming angle from normal different.

\section{CONCLUSION}

The objective was determining the angle of the wheels which is done by ackerman's principle. The results of the angle are obtained by using serial data transmission by max 232 using the microcontroller ATMega16. The readings shown in the computer is determined by using the frequency of oscillator, prescalar and frequency which is equal to $50 \mathrm{~Hz}$. It takes the data from microcontroller and sends it through USART. The above experiment and theory can also be applicable for the 4-wheel driving vehicle. Ackermann geometry is to avoid the need for tires to slip sideways when following the path around a curve.

\section{REFERENCES}

[1] P. A. Simionescu and D. Beale, "Optimum synthesis of the four-bar function generator in its symmetric embodiment: the Ackermann steering linkage," Mech Mach Theory, vol. 37, no. 12, pp. 1487-1504, 2002, doi: 10.1016/S0094-114X(02)00071-X.

[2] P. A. Simionescu and S. R. Smith, "Initial estimates in the design of central-lever steering linkages," J. Mech. Des., vol. 124, no. 4, pp. 646-651, 2002, doi: 10.1115/1.1505853.

[3] A. G. Erdman, G. N. Sandor, and S. Kota, "Mechanism design: analysis and synthesis," Englewood Cliffs, NJ: Prentice Hall, pp. 12-19, 2001, doi: 10.1016/j.mechmachtheory.2008.02.014.

[4] A. R. Hanzaki, P. V. M. Rao, and S. K. Saha, "Kinematic and sensitivity analysis and optimization of planar rack-and-pinion steering linkages," Mechanism and Machine Theory, vol. 44, no. 1, pp. 42-56, 2009, doi: 10.1016/j.mechmachtheory.2008.02.014

[5] E. Chicurel, "A steering interval mechanism," Mech Mach Theory, vol. 34, no. 3, pp. 421-436, 1999, doi: 10.1016/S0094-114X(98)00046-9.

[6] D. D. Ardayfio and D. Qiao, "Analytical design of seven joint spatial steering mechanisms," Mech Mach Theory, vol. 22, no. 4, pp. 315-319, 1987, doi: 10.1016/0094-114X(87)90020-6.

[7] M. L. Felzien and D. Cronin, "Steering error optimization of the Macpherson strut automotive front suspension," Mech Mach Theory, vol. 20, no. 1, pp. 17-26, 1985, doi: 10.1016/0094-114X(85)90054-0.

[8] D. A. Mantaras, L. Pablo, and V. Carlos, "Development and validation of a three-dimensional kinematic model for the McPherson steering and suspension mechanisms," Mechanism and Machine Theory, vol. 39, no. 6, pp. 603-619, 2004, doi: 10.1016/j.mechmachtheory.2003.12.006.

[9] A. Carcaterra and W. D'Ambrogio, "A function generating differential mechanism for an exact solution of the steering problem," Mechanism and Machine Theory, vol. 33, no. 5, pp. 535-549, 1998, doi: 10.1016/S0094-114X(97)00072-4.

[10] M. Raghavan, "Number and dimensional synthesis of independent suspension mechanisms," Mechanism and Machine Theory, vol. 31, no. 8, pp. 999-1195, doi: 10.1016/0094-114X(96)84605-2.

[11] X. Huang and Y. Zhang, "Reliability sensitivity analysis for rack-and-pinion steering linkages" J. Mech. Des., vol. 132, no. 7, 2010, doi: 10.1115/1.4001901.

[12] T. Emura and A. Arakawa, "A new steering mechanism using noncircular gears," JSME Int J., vol. 35, no. 4, pp. 604-610, 1992, doi: 10.1299/jsmec1988.35.604. 
[13] D. B. Donner, "Function generation utilizing an eight-link mechanism and optimized non-circular gear elements with application to automotive steering," Proc IMechE, Part C: J Mechanical Engineering Science, vol. 215, no. 7, pp. 847-857, 2001, doi: 10.1243/0954406011524090.

[14] G. Miller, R. Reed, and F. Wheeler, "Optimum Ackerman for improved steering axle tire wear on trucks," $S A E$ Technical Paper, 1991, doi: 10.4271/912693.

[15] R. Palanisamy and V. Krishnasamy, "A 3D-space vector modulation algorithm for three phase four wire neutral point clamped inverter systems as power quality compensator," Energies, vol. 10, no. 11, 2017, doi: 10.3390/en10111792.

[16] R. Palanisamy, K. Vijayakumar, and B. Karthikeyan, "Hybrid Energy Source Fed Fuzzy-Based SVPWM for 5Level NPC Inverter with Grid Connected System," Journal of Circuits, Systems and Computers, vol. 30, no. 10, 2021, doi: $10.1142 / \mathrm{S} 0218126621501802$.

[17] S. G. Fernandez, R. Palanisamy, and K. Vijayakumar, "GPS \& GSM based accident detection and auto intimation," Indonesian Journal of Electrical Engineering and Computer science, vol. 11, no. 1, pp. 356-36, 2018, doi: 10.11591/ijeecs.v11.i1.pp356-361.

[18] D. Selvabharathi and N. Muruganantham, "Experimental analysis on battery based health monitoring system for electric vehicle," Materials Today: Proceedings, vol. 45, 2021, pp. 1552-1558, doi: 10.1016/j.matpr.2020.08.303.

[19] R. Palanisamy and K. Vijayakumar, "Paper SVPWM for 3-phase 3-level neutral point clamped inverter fed induction motor control," Indonesian Journal of Electrical Engineering and Computer Science, vol. 9, no. 3, pp. 703-710, 2018, doi: 10.11591/ijeecs.v9.i3.pp703-710.

[20] C. Hottentot, V. Meines, and M. Pinckaers, "Experiments on autonomous and automated driving: an overview 2015," ANWB The Hague report). Retrieved on September3 (2015), 2018.

[21] S. Pramanik, "Kinematic synthesis of a six-member mechanism for automotive steering," J Mech Des, vol. 124, no. 4, pp. 642-645, 2002, doi: 10.1115/1.1503372.

[22] R. Palanisamy, T. H. A. Singh, A. Ranjan, and J. Singh, "BLDC motor driven electric skateboard using SVPWM," International Journal of Electrical and Computer Engineering, vol. 10, no. 1, pp. 711-718, 2020, doi: 10.11591/ijece.v10i1.pp711-718.

[23] S. G. Fernandez et al., "Unmanned and autonomous ground vehicle" International Journal of Electrical and Computer Engineering, vol. 9, no. 5, pp. 4466-4472, 2019, doi: 10.11591/ijece.v9i5.pp4466-4472.

[24] C. Suh and A. W. Mecklenburg, "Optimal design of mechanisms with the use of matrices and least squares," Mech Mach Theory, vol. 8, pp. 479-495, 1973, doi: 10.1016/0094-114X(73)90022-0.

[25] K. Hojjati-Emami, B. S. Dhillon, and K. Jenab, "Reliability prediction for the vehicles equipped with advanced driver assistance systems (ADAS) and passive safety systems (PSS)," Int. J. Indust. Eng. Comput, vol. 3, no. 5, pp. 731-742, 2012, doi: 10.5267/j.ijiec.2012.08.004.

[26] P. A. Simionescu and I. Talpasanu, "Synthesis and analysis of the steering system of an adjustable tread-width fourwheel tractor," Mech Mach Theory, vol. 42, no. 5, pp. 526-540, 2007, doi: 10.1016/j.mechmachtheory.2006.06.001. 